\title{
Recorrência de concepções alternativas sobre corrente elétrica em circuitos simples
}

\author{
Recurrency of alternative conceptions about electrical current in simple circuits
}

\author{
Francisco Andreázio Lôbo de Andrade ${ }^{1}$, Geovani Ferreira Barbosa ${ }^{1}$, Fernando Lang da Silveira ${ }^{2}$, \\ Carlos Alberto dos Santos*1@ \\ ${ }^{1}$ Universidade Federal Rural do Semiárido, Centro de Ciências Exatas e Naturais, Mossoró, RN, Brasil \\ ${ }^{2}$ Universidade Federal do Rio Grande do Sul, Instituto de Física, Porto Alegre, RS, Brasil
}

Recebido em 10 de Janeiro, 2018. Revisado em 06 de Março, 2018. Aceito em 14 de Março, 2018.

\begin{abstract}
Descreve-se neste trabalho resultados recentes, obtidos com 32 alunos do Ensino Médio a respeito de concepções alternativas sobre corrente elétrica em circuitos simples. Utilizou-se um teste de 14 itens elaborado no IF-UFRGS e validado após aplicação a alunos de engenharia da mesma universidade, em 1989. No presente experimento, 7 alunos foram selecionados para entrevistas clínicas, a partir do padrão de respostas no teste escrito. Os resultados do teste escrito foram comparados àqueles obtidos na UFRGS e analisados no contexto da literatura internacional pertinente ao tema. Confirmou-se a recorrência de concepções alternativas já amplamente relatada por autores de diversos países em diferentes continentes. As entrevistas clínicas permitiram uma investigação mais detalhada deste fenômeno e sinalizaram a necessidade de novas abordagens didáticas no ensino de circuitos elétricos.

Palavras-chave: concepções alternativas, circuitos elétricos, corrente elétrica, eletricidade, entrevista clínica.
\end{abstract}

\begin{abstract}
This paper describes recent results obtained with 32 students from the Middle School regarding alternative conceptions about electric current in simple circuits. A 14-item test developed at IF-UFRGS was used and validated after application to engineering students from the same university in 1989. In the present experiment, 7 students were selected for clinical interviews, from the standard of answers in the written test. The results of the written test were compared to those obtained at UFRGS and analyzed in the context of the international literature relevant to the topic. The recurrence of alternative conceptions, as observed in the present investigation, has already been widely reported by authors from different countries on different continents. The clinical interviews allowed a more detailed investigation of this phenomenon and signaled the need for new didactic approaches in the teaching of electrical circuits.
\end{abstract}

Keywords: alternative conceptions, electric circuits, electric current, electricity, clinical interview.

\section{Introdução}

De tudo que se sabe hoje sobre o processo de ensinoaprendizagem, talvez a coisa mais importante possa ser resumida em uma frase: descubra o que seu aluno já sabe e ensine de acordo. O significado dessa frase aparece em diferentes teorias da aprendizagem, sob diferentes formas. Ao propor uma pedagogia para a educação de adultos, em um processo dialógico baseado no universo vocabular do aprendiz, Paulo Freire escreve [1]: "quem dialoga, dialoga com alguém sobre alguma coisa" (p.69). A frase sugere que essa "alguma coisa" é o que o aluno já sabe. Ao discutir sua teoria de aprendizagem, Bruner enfatiza que a eficiência de uma sequência de ensino depende do cabedal de informações e do estágio de desenvolvimento do aluno a quem se destina [2,3]. A frase acima também tem a ver com as ideias de Vygotsky a respeito do que ele define como zona de desenvolvimento proximal [4]. Por trás desses significados, está a estrutura cognitiva, um

*Endereço de correspondência: cas.ufrgs@gmail.com conceito muito debatido entre os psicólogos nos anos 19401950, e que foi objeto de inúmeros estudos experimentais com ratos [5-8].

No início dos anos 1960, Ausubel formalizou o conhecimento acumulado até então, naquilo que hoje conhecemos como Teoria da Aprendizagem Significativa [9-12]. Ausubel tem como premissas a importância da aprendizagem significativa em oposição à aprendizagem mecânica, e a ênfase na estrutura de conhecimento do aprendiz como determinantes para a aquisição e retenção do conhecimento [11]. A teoria de Ausubel deixa duas questões em aberto: como ter acesso à estrutura cognitiva e como organizar o conteúdo de modo a propiciar uma aprendizagem significativa, tendo em conta a topologia típica da estrutura cognitiva do público-alvo. Tais questões foram objeto de inúmeros estudos nos anos 1970 [13-16] e desembocaram em duas instigantes linhas de pesquisa: modelos mentais [17-20] e concepções alternativas, cujos trabalhos pioneiros estão descritos em duas teses de doutorado. A primeira defendida por Rosalind Driver 
em 19741 e a segunda defendida por Laurence Viennot em 1977 [21]. Em 1994, Rosalind Driver e colaboradores publicaram um livro sistematizando seus resultados em 20 anos de atividades [22].

O tema do qual estamos tratando é geralmente designado na literatura em inglês pela palavra misconception, e eventualmente pela palavra preconception. Apesar de verbalmente similares, essas palavras podem ter significados bem diferentes no contexto educacional. Embora pudesse ser interessante, não cabe aqui uma discussão da etimologia dessas palavras. Ao leitor interessado recomenda-se o artigo de John Clement [23], que também discute a validade do uso da expressão alternative conceptions. Os francófonos usualmente preferem essa última designação, que em seu idioma é conceptions spontanées. No Brasil e em Portugal costuma-se usar indistintamente concepções espontâneas e concepções alternativas, sendo esta última a expressão que preferimos.

Qualquer que seja a expressão utilizada, o que se pretende investigar é até que ponto a estrutura conceitual apropriada por um indivíduo como resultado de sua vivência escolar e de suas observações cotidianas corresponde àquela aceita pela comunidade científica. $\mathrm{Ou}$, dito de outro modo, que modelo mental corresponde à organização conceitual presente na estrutura cognitiva de um indivíduo? Quando há conflito entre essas estruturas e as concepções científicas, diz-se que o indivíduo apresenta concepções alternativas. Esse tipo de investigação foi realizado por inúmeros estudiosos em diferentes áreas do conhecimento, mas aqui vamos restringir a discussão à literatura sobre circuitos elétricos simples, e mesmo assim, dada a extensa literatura disponível, optamos por referir apenas os trabalhos que consideramos mais relevantes em termos de precedência, aderência ao escopo do presente trabalho, e facilidade de acesso. Todavia, pelo caráter inovador, consideramos importante chamar a atenção para trabalhos recentes, conectando as respostas a testes similares aos que serão discutidos a seguir com a atividade cerebral como vista por meio de imagens de ressonância magnética $[24,25]$.

O que estamos denominando circuitos elétricos simples são associações em série e paralelo de resistores ou lâmpadas alimentadas por fontes de tensão. Ao longo das últimas quatro décadas, testes similares foram aplicados a estudantes de todos os níveis de ensino, da educação básica à universitária, em todos os continentes [26-32], com resultados impressionantemente similares em termos de concepções alternativas, e pouco dependentes do grau de instrução anterior ao teste. Análises detalhadas desses resultados proporcionaram a identificação de vários modelos mentais baseados em concepções alternativas. Muitos desses modelos, embora similares, são apresen-

\footnotetext{
${ }^{1}$ Driver, R. P. (1974). The representation of conceptual frameworks in young adolescent science students. Dissertation Abstracts International, 34(11-A), 7065. Informação extraída do site da American Psychological Association (http://psycnet.apa.org/record/ 1976-13289-001), em 1/11/2017.
}

tados na literatura com diferentes nomes e atributos (modelo linear, modelo não conservativo, modelo local, modelo sequencial, etc.) $[18,29,33-38]$. Em alguns casos há ambiguidade no rótulo, de modo que preferimos apenas enumerar os modelos mais recorrentes e que podem ocorrer de forma concomitante:

- Modelo I - A corrente elétrica é emitida pela fonte (bateria, pilha ou gerador) a partir de um dos polos e é consumida durante sua passagem no circuito, de modo que sua intensidade diminui ao ultrapassar algum elemento do circuito.

- Modelo II - Correntes elétricas deixam a fonte a partir de ambos os polos, sendo usadas quando se encontram nos elementos do circuito.

- Modelo III - A intensidade da corrente é determinada pelo elemento através do qual ela está passando. Ela não pode ser influenciada por um elemento onde ainda não passou. Ou seja, a corrente é vista como algo que atravessa o circuito ponto a ponto, afetando cada elemento no momento que o atinge. Assim, uma mudança em um ponto do circuito não afeta o comportamento do circuito nos pontos anteriores.

- Modelo IV - A corrente é uma propriedade exclusiva do gerador. Ela é independente dos demais elementos do circuito.

No curso de uma intervenção pedagógica em uma turma do ensino médio de uma escola pública do Ceará, utilizamos um teste para verificar se após a intervenção os alunos possuíam concepções científicas sobre corrente elétrica em circuitos simples. Após a análise dos resultados observamos algumas semelhanças com os resultados obtidos com esse mesmo teste, quando aplicado a alunos de engenharia da UFRGS em 1988 [28]. Decidimos realizar um estudo comparativo detalhado, cujos resultados serão apresentados a seguir. Confirmaram-se relatos anteriores, segundo os quais a recorrência de algumas concepções alternativas independem da localidade e do nível de aprendizagem formal da população.

\section{O teste Silveira, Moreira e Axt (Teste SMA)}

Em 1988, Silveira, Moreira e Axt elaboraram e validaram um teste para verificar se alunos de engenharia possuíam concepções científicas sobre corrente elétrica em circuito simples [28]. Constituído de 14 itens, o teste contém questões dos autores e questões tiradas da literatura, com a devida citação bibliográfica. Na descrição dos autores [28]:

Todos os itens possuem três alternativas: uma dessas alternativas é coerente com concepções científicas sobre corrente elétrica, enquanto as outras duas são coerentes com concepções alternativas, principalmente com o modelo 
não conservativo, segundo o qual a corrente vai sendo consumida em cada componente do circuito de modo que os últimos recebem menos corrente (ou brilham menos, no caso, por se tratar de lâmpadas).

Daqui em diante denominaremos esse teste pela sigla SMA. Reproduziremos aqui apenas as questões que serão objeto de discussão e comparação entre as duas populações.

\section{Resultados do teste em amostras de duas populações diferentes}

O Teste SMA foi aplicado em duas amostras de populações completamente diferentes, tanto em termos de nível de aprendizagem, quanto em termos geográficos. A amostra que chamaremos FisII, consistiu em 121 alunos de Física II-C, disciplina sobre eletricidade e magnetismo ministrada nos cursos de engenharia da UFRGS. O teste foi aplicado em 1988, após o estudo de corrente elétrica e de circuitos elétricos simples. O livro-texto básico utilizado nessa disciplina é o volume 3 do Halliday-Resnick [39].

A amostra que chamaremos EnsMed consistiu em 32 alunos do $3^{\circ}$. Ano do ensino médio de uma escola pública de Maracanaú (Ce), com Indicador de Nível Socioeconômico (INSE) Médio Baixo, conforme definição do INEP ${ }^{2}$. A turma participou de um experimento educacional para testar uma Unidade de Ensino Potencialmente significativa (UEPS) [40] sobre eletricidade e magnetismo, fazendo uso do método de ensino baseado em projetos. No primeiro semestre os alunos tiveram aulas convencionais sobre eletricidade e magnetismo utilizando o volume 3 da obra Física: Interação e Tecnologia [41]. Antes de iniciarem os projetos a serem realizados no segundo semestre, eles responderam o teste SMA, cujos resultados serão discutidos a seguir.

Os resultados obtidos com as duas amostras são apresentados em porcentagem de acertos na Tabela 1. As respostas com índice 1 correspondem à amostra EnsMed,

2 http://download.inep.gov.br/informacoes_estatisticas/ indicadores_educacionais/2011_2013/nivel_socioeconomico/ nota_tecnica_indicador_nivel_socioeconomico.pdf enquanto aquelas com índice 2 correspondem à amostra FisII. O teste do chi-quadrado $\left(\chi^{2}\right)$ foi realizado para verificar se os dois grupos são amostras de populações com a mesma distribuição de frequência nas alternativas de cada questão. Os valores de $\chi^{2}$, bem como os respectivos níveis de significância (ns) também são apresentados na Tabela 1.

A média de acertos da FisII foi 9,03, enquanto da EnsMed foi 5,31. O teste $\mathrm{t}$ para esses dois resultados forneceu $\mathrm{t}=8,96$, com ns $<0,001$. Portanto, do ponto de vista de média de acertos essas duas amostras são significativamente diferentes. Outro parâmetro de comparação entre as amostras é o valor de $\chi^{2}$. Como se sabe, quanto mais alto o valor obtido para o $\chi^{2}$, mais discrepantes são as duas distribuições de frequências. Nesse sentido, comparamos as duas amostras separando as questões em três grupos: (1) questões para as quais $\chi^{2} \leq 10$ (questões $1,4,6,8)$; (2) questões com valores intermediários de $\chi^{2}$, ou seja $10<\chi^{2} \leq 50$ (questões $3,5,9,10,12,14$ ); (3) questões para as quais $\chi^{2}>50$ (questões $2,7,11$, 13). Na sequência discutiremos as questões enquadradas nesses limites.

Sete alunos, cujas respostas mostraram forte indicação da presença de concepções alternativas foram entrevistados por um dos autores (CAS) utilizando a ferramenta Whatsapp e seguindo procedimentos similares àqueles sugeridos na literatura $[26,42,43]$. As respostas desses alunos são apresentadas na Tabela 2. As entrevistas clínicas realizadas nesse estudo, cujos trechos mais relevantes são apresentados no material suplementar, têm o único objetivo de detectar com maior precisão as concepções alternativas sugeridas pelos alunos no teste escrito. Nesse sentido, os questionamentos do entrevistador serão sempre feitos seguindo a linha de raciocínio de cada entrevistado, de modo a não interferir em sua estrutura mental.

Convém chamar a atenção para o fato de que nossa amostragem não permite um estudo estatístico confiável em termos da análise de consistência interna do teste, nem do grau de dificuldade do mesmo, uma vez que o número de respondentes é aproximadamente igual ao número de questões no teste. Todavia, várias das observações que a seguir relataremos, foram também relatadas em um

Tabela 1: Resultados percentuais do Teste SMA aplicados em: (a) uma turma do ensino médio de uma escola de Maracanaú (Ce), com índice INSE Médio Baixo. Respostas A1, B1 e C1; (b) uma turma de Física II-C dos cursos de engenharia da UFRGS.

\begin{tabular}{|c|c|c|c|c|c|c|c|c|c|c|c|c|c|c|}
\hline Questão / Opção & 1 & 2 & 3 & 4 & 5 & 6 & 7 & 8 & 9 & 10 & 11 & 12 & 13 & 14 \\
\hline A1 & 0 & $7^{*}$ & 75 & $50^{*}$ & 6 & 16 & 3 & 41 & $47^{*}$ & 19 & 75 & 75 & $6^{*}$ & 6 \\
\hline B1 & 0 & 9 & $25^{*}$ & 44 & $13^{*}$ & $78^{*}$ & 94 & 38 & 15 & 12 & $3^{*}$ & $3^{*}$ & 69 & 69 \\
\hline C1 & $100^{*}$ & 84 & 0 & 6 & 81 & 6 & $3^{*}$ & $21^{*}$ & 38 & $69^{*}$ & 22 & 22 & 25 & $26^{*}$ \\
\hline A2 & 10 & $69^{*}$ & 26 & $62^{*}$ & 8 & 7 & 40 & 27 & $87^{*}$ & 3 & 13 & 31 & $79^{*}$ & 13 \\
\hline $\mathrm{B} 2$ & 2 & 26 & $70^{*}$ & 31 & $75^{*}$ & $70^{*}$ & 22 & 28 & 12 & 9 & $38^{*}$ & $38^{*}$ & 9 & 25 \\
\hline $\mathrm{C} 2$ & $88^{*}$ & 5 & 4 & 8 & 17 & 23 & $38^{*}$ & $45^{*}$ & 1 & $88^{*}$ & 49 & 31 & 12 & $58^{*}$ \\
\hline$\chi^{2}$ & 4,4 & 98,4 & 27,0 & 1,7 & 49,7 & 6,3 & 57,0 & 5,5 & 45,4 & 12,9 & 51,2 & 23,7 & 69,8 & 17,2 \\
\hline ns & 0,12 & 0,00 & 0,00 & 0,43 & 0,00 & 0,04 & 0,00 & 0,07 & 0,00 & 0,02 & 0,00 & 0,00 & 0,00 & 0,00 \\
\hline
\end{tabular}

A1, B1, C1 (Ensino Médio). A2, B2, C2 (Física II-C). * - frequência na resposta correta. ns é o nível de significância no teste $\chi^{2}$. 
Tabela 2: Respostas dos sete alunos selecionados para entrevista clínica. As alternativas corretas são apresentadas abaixo do número de cada questão. $\mathrm{O}$ total de respostas corretas de cada aluno é apresentado abaixo de seu respectivo nome fictício.

\begin{tabular}{|c|c|c|c|c|c|c|c|c|c|c|c|c|c|c|}
\hline & $1 \mathrm{C}$ & $2 \mathrm{~A}$ & $3 \mathrm{~B}$ & $4 \mathrm{~A}$ & $5 \mathrm{~B}$ & $6 \mathrm{~B}$ & $7 \mathrm{C}$ & $8 \mathrm{C}$ & $9 \mathrm{~A}$ & $10 \mathrm{C}$ & $11 \mathrm{~B}$ & $12 \mathrm{~B}$ & $13 \mathrm{~A}$ & $14 \mathrm{C}$ \\
\hline $\begin{array}{c}\text { Aluna1 } \\
7\end{array}$ & $\mathrm{C}$ & B & $\mathrm{A}$ & $\mathrm{A}$ & B & B & B & $\mathrm{C}$ & B & $\mathrm{C}$ & $\bar{A}$ & $\bar{A}$ & $\mathrm{C}$ & $\mathrm{C}$ \\
\hline $\begin{array}{c}\text { Aluno } 2 \\
3\end{array}$ & $\mathrm{C}$ & $\mathrm{C}$ & $\mathrm{A}$ & B & $\mathrm{A}$ & $\mathrm{C}$ & B & B & $\mathrm{A}$ & $\mathrm{A}$ & $\mathrm{C}$ & $\mathrm{C}$ & $\mathrm{C}$ & $\mathrm{C}$ \\
\hline $\begin{array}{c}\text { Aluna3 } \\
5\end{array}$ & $\mathrm{C}$ & $\mathrm{C}$ & $\mathrm{A}$ & $\mathrm{A}$ & $\mathrm{A}$ & B & B & $\mathrm{C}$ & B & $\mathrm{C}$ & $\mathrm{A}$ & B & B & $\mathrm{A}$ \\
\hline $\begin{array}{c}\text { Aluna } 4 \\
6 \\
\end{array}$ & $\mathrm{C}$ & B & $\mathrm{A}$ & $\mathrm{A}$ & $\mathrm{C}$ & B & B & $\mathrm{C}$ & $\mathrm{A}$ & $\mathrm{A}$ & A & A & $\mathrm{A}$ & B \\
\hline $\begin{array}{c}\text { Aluna } 5 \\
7\end{array}$ & $\mathrm{C}$ & $\mathrm{C}$ & $\mathrm{A}$ & $\mathrm{A}$ & $\mathrm{C}$ & B & B & $\mathrm{C}$ & $\mathrm{A}$ & $\mathrm{C}$ & $\mathrm{A}$ & $\mathrm{C}$ & $\mathrm{A}$ & B \\
\hline $\begin{array}{c}\text { Aluno6 } \\
5\end{array}$ & $\mathrm{C}$ & $\mathrm{C}$ & $\mathrm{A}$ & B & $\mathrm{C}$ & B & B & $\mathrm{A}$ & $\mathrm{A}$ & $\mathrm{C}$ & $\mathrm{A}$ & $\mathrm{C}$ & $\mathrm{A}$ & B \\
\hline $\begin{array}{c}\text { Aluno7 } \\
9\end{array}$ & $\mathrm{C}$ & $\mathrm{A}$ & B & $\mathrm{A}$ & B & $\mathrm{A}$ & $\mathrm{C}$ & $\mathrm{A}$ & $\mathrm{A}$ & $\mathrm{A}$ & $\mathrm{A}$ & $\mathrm{A}$ & $\mathrm{A}$ & $\mathrm{C}$ \\
\hline
\end{tabular}

estudo com o devido rigor estatístico, e replicado em diferentes países $[44,45]$.

\subsection{Questões para as quais $\chi^{2} \leq 10$}

Todas as questões desse grupo, excetuando a 8, caracterizamse pelo fato da maioria dos alunos terem respondido corretamente as questões e por inexistirem diferenças importantes entre os dois grupos de alunos. Na questão $8,45 \%$ dos alunos de FisII escolheram a alternativa correta(C), enquanto apenas $21 \%$ da turma EnsMed escolheram esta opção. Por quê essa questão tem baixo valor de $\chi^{2}$ ? Porque a razão 45/21 na alternativa correta (C), praticamente foi invertida na opção (A). Ou seja nessa opção tivemos $27 / 41$. Essa questão refere-se a um circuito RC, um tema superficialmente abordado no ensino médio. E mesmo entre os alunos de engenharia trata-se de um tema pouco compreendido, basta ver a dispersão de respostas em ambas as turmas. Na turma EnsMed, as frequências percentuais (A/B/C) foram $(41 / 38 / 21)$, enquanto na turma FisII foram $(27 / 28 / 45)$. Então, por se tratar de um tema pouco estudado no ensino médio, excluiremos essa questão de nossa análise. Vamos analisar os resultados apresentados na Tabela 3 , referentes às questões 1,4 e 6 .

\subsubsection{Questão 1}

A questão 1 é exibida na Fig. 1. Trata-se de uma das clássicas questões usadas para testar o Modelo II, aquele que se refere ao entendimento de que a corrente é consumida ao longo do circuito. A surpresa aqui é que todos os alunos do ensino médio acertaram a questão, ao passo

Tabela 3: Percentuais das respostas corretas nos dois grupos de alunos nas questões para as quais $\chi^{2} \leq 10$. Alternativas corretas entre parênteses.

\begin{tabular}{lccc}
\hline Questão (alternativa correta) & $1(\mathrm{C})$ & $4(\mathrm{~A})$ & $6(\mathrm{~B})$ \\
\hline Ensino Médio & 100 & 50 & 78 \\
\hline Física II-C & 88 & 62 & 70 \\
\hline
\end{tabular}

que $12 \%$ dos alunos de Física II-C optaram pelas alternativas erradas. A alternativa A foi escolhida por $10 \%$ dos alunos, enquanto $2 \%$ optaram pela B. Esta última alternativa é escolhida por quem acredita que a corrente é consumida e imagina que ela circula do polo negativo para o positivo da bateria, ou seja, quem raciocina com o Modelo I.

Como todos os alunos da turma EnsMed responderam corretamente essa questão, supõe-se que eles não apresentam a concepção alternativa do consumo de corrente. Então ela foi utilizada na entrevista clínica para investigar que sentido cada aluno atribui à corrente elétrica no circuito.

Os livros didáticos costumam definir duas direções da corrente elétrica em um circuito simples. Uma na direção do polo positivo da bateria para o negativo e outra na direção inversa. Vejamos exatamente como Halliday e Resnick apresentam essas direções [39]:

Na Fig. 1b, traçamos as ramificações da corrente no sentido que a portadora de carga positiva - repelida pelo terminal positivo da bateria e atraída pelo terminal negativo - circularia em volta da malha. Na realidade 3 os portadores de carga na malha de cobre da Fig. 1b são elétrons que possuem uma carga negativa. Eles circulam em direção oposta à das ramificações da corrente (p. 97).

Além desses dois modelos muito difundidos, e que eventualmente produzem concepções alternativas, há relatos na literatura de um terceiro modelo, absolutamente baseado em concepções espontâneas. Trata-se do que se chama de modelo do choque de correntes (clashing model) $[22,33]$, geralmente exibido por crianças. De acordo com esse modelo, a corrente sai de ambos os polos da bateria e se chocam nas lâmpadas para produzirem a luminosidade.

\footnotetext{
3 Na edição em pauta há um erro de tradução. Em vez de "Na realidade", consta "Atualmente". ACTUALLY foi traduzida como se fosse CURRENTLY.
} 
1) No circuito da figura 1 pode-se afirmar que:

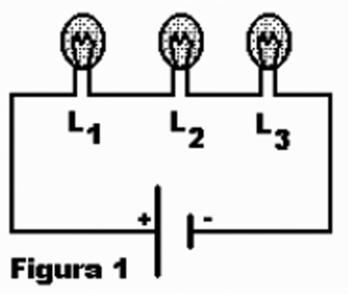
a) $L_{1}$ brilha mais do que $L_{2}$ e esta mais do que $L_{3}$.
b) $L_{3}$ brilha mais do que $L_{2}$ e esta mais do que $L_{1}$.

c) as três lâmpadas têm o mesmo brilho.

Figura 1: Questão 1 do Teste SMA.

Entre os sete alunos selecionados para a entrevista clínica, o Aluno6 foi considerado pelo seu professor (FALA) como o mais inteligente da classe. Essa avaliação subjetiva foi compartilhada pelo entrevistador (CAS), quando comparou suas respostas às dos outros entrevistados. Todavia, como pode-se ver na Tabela 2, apenas o Aluno2, acertou menos questões do que o Aluno6. Pode ser que seja fraca a correlação entre a pontuação no teste SMA e a avaliação subjetiva de inteligência dos alunos.

Embora todos os alunos tenham optado pela alternativa correta, $\mathrm{C}$, na questão 1 , durante as entrevistas apenas o Aluno6 foi taxativo em afirmar que havia optado por essa resposta. Alguns dos outros seis entrevistados responderam que não lembravam que alternativa tinham escolhido, enquanto outros pensaram ter escolhido uma alternativa diferente (ver material suplementar).

Ao longo de toda a entrevista o aluno6 demonstrou consistência em seu raciocínio, mesmo quando orientado por concepções alternativas. Na resposta à primeira questão ele mostrou claramente seguir parte do Modelo I, ao dizer que a corrente sai no polo negativo e entra no positivo. Essa concepção pode ser justificada para quem pensa no movimento de deriva dos portadores, no deslocamento de elétrons através do circuito, mas o aluno não foi explícito quanto a isso. Por outro lado, ele não apresentou sinais de seguir a parte do Modelo I, segundo a qual a corrente é consumida ao longo do circuito. Para ele, a corrente é a mesma nas três lâmpadas. Em suma, esse aluno tem um modelo consistente com os textos didáticos mais utilizados no ensino médio, ou seja, a corrente circula de um polo da bateria para outro, através do circuito. Nesse trajeto a corrente produz luminosidade nas lâmpadas, cujo brilho cresce se a intensidade da corrente aumenta. A Tabela 4 apresenta os principais aspectos das respostas à questão 1 de todos os alunos entrevistados.

Curiosamente apenas um dos alunos entrevistados apresentou o Modelo II, tão frequentemente relatado na literatura $[27,29,34,37,38,44,46,47]$. Por outro lado, vários associaram corrente à energia, uma confusão relatada por muitos autores $[27,29,34,44,48]$.

\subsubsection{Questão 4}

O enunciado da questão 4 é apresentado na Fig. 2. É impressionante como as duas turmas apresentam o mesmo padrão de respostas, o que é consistente com o baixo valor do chi-quadrado $\left(\chi^{2}=1,7\right)$. A maioria escolheu a opção correta (A), mas uma boa proporção optou pela

Tabela 4: Principais aspectos das respostas à questão 1. A: Consumo de corrente; B: Relação direta entre corrente e brilho; C: Choque de correntes; D: Sentido da corrente (1:+para-; 2:-para+).

\begin{tabular}{|c|c|c|c|c|c|}
\hline Aluno & $\mathrm{A}$ & $\mathrm{B}$ & $\mathrm{C}$ & $\mathrm{D}$ & Outras respostas \\
\hline 1 & Não & $?$ & $?$ & 1 & $\begin{array}{l}\text { As lâmpadas apresentam o mesmo brilho porque "estão no mesmo circuito", mas não tem a menor } \\
\text { a ideia da causa da luminosidade na lâmpada. }\end{array}$ \\
\hline 2 & Não & $?$ & Não & $?$ & $\begin{array}{l}\text { A corrente que passa pelo circuito alimenta as três lâmpadas de igual forma. A corrente vem da } \\
\text { energia elétrica. Aluno muito confuso em relação ao sentido da corrente. Ora pensa que é do polo } \\
\text { positivo para o negativo, ora pensa que é o contrário. }\end{array}$ \\
\hline 3 & Não & $?$ & Não & & $\begin{array}{l}\text { As três lâmpadas têm o mesmo brilho porque "estão na mesma linha e a energia vai passar pelas } \\
\text { três com a mesma intensidade". L3 é a primeira lâmpada que recebe energia, pois esta sai do polo } \\
\text { negativo. } \\
\text { Não tem a menor ideia da causa microscópica da luminosidade da lâmpada. }\end{array}$ \\
\hline 4 & Não & $?$ & Não & 1 & $\begin{array}{l}\text { As lâmpadas têm o mesmo brilho porque a energia passa por todas igualmente. A energia sai do } \\
\text { polo positivo. A energia é transportada pela corrente elétrica. }\end{array}$ \\
\hline 5 & Não & $?$ & Sim & $?$ & $\begin{array}{l}\text { As três lâmpadas apresentam o mesmo brilho "pelo fato de ser um circuito em série. Todas recebem } \\
\text { a mesma energia". O brilho vem da energia que as lâmpadas recebem. "Elas precisam tanto de } \\
\text { prótons, quanto de elétrons" }\end{array}$ \\
\hline 6 & Não & Sim & Não & 2 & Todas as respostas do Aluno6 foram transcritas acima. \\
\hline 7 & Sim & $?$ & Sim & $?$ & $\begin{array}{l}\text { Associa corrente à energia. Achou inicialmente que o brilho é mais forte em L3 porque é o momento } \\
\text { do primeiro encontro entre a corrente positiva e a negativa. Quando questionado do porquê, mudou } \\
\text { de ideia e respondeu que as três lâmpadas recebem a mesma carga, mas permaneceu com o modelo } \\
\text { do choque de correntes. }\end{array}$ \\
\hline
\end{tabular}




\section{4) No circuito da Figura 4, I é ulm interruptor aberto. Ao fechá-lo:}

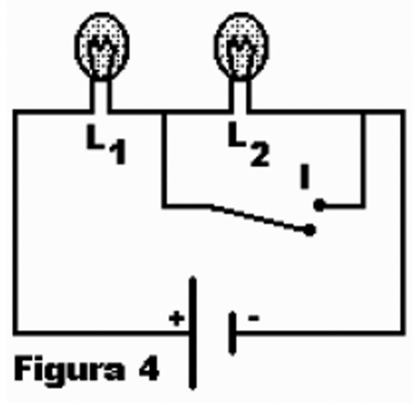

a) aumenta o brilho de $L_{1}$.

b) $\circ$ brilho de $L_{1}$ permanece o mesmo.

c) diminui o brilho de $L_{1}$.

Figura 2: Questão 4 do Teste SMA.

opção (B), ou seja 44\% dos alunos da turma EnsMed e $31 \%$ da FisII disseram que o brilho de L1 permanece o mesmo. Esse tipo de resposta engloba uma concepção alternativa e uma dificuldade em reconhecer o estado de curto-circuito.

A concepção alternativa corresponde ao Modelo III, ou seja ligar ou desligar o interruptor não tem qualquer efeito sobre L1, porque esse ato ocorre depois que a corrente passa por L1. Respostas similares de alunos do ensino médio $[34,44,45,49]$ e da universidade $[44,45,50]$ são apresentadas na literatura. Esse tipo de raciocínio é consistente com a noção da corrente convencional, aquela que circula no sentido do polo positivo da bateria para o negativo. Mais adiante veremos como o Aluno6 trata essa questão, uma vez que para ele a corrente circula do polo negativo para o positivo.

A dificuldade em reconhecer o estado de curto-circuito também tem sido relatada na literatura. Em sua tese de doutorado, Paula Engelhardt [44,45] elaborou uma questão similar à questão 4 do presente trabalho, para avaliar a capacidade de alunos do ensino médio e de engenharia para reconhecer o estado de curto-circuito. A questão 18 do Direct, v.1.0 [44,45] apresentava quatro circuitos: um normal, um em curto e dois abertos. Os dois primeiros eram similares a esses apresentados na Fig. 3. O circuito (B) está em curto, logo a corrente não passa pela lâmpada. No entanto, $67 \%$ dos estudantes de engenharia e $70 \%$ dos estudantes do ensino médio responderam que as lâmpadas brilham em ambos os circuitos [45]. Comparando os percentuais apresentados por Engelhardt e os obtidos em nossos estudos, podemos dizer que os alunos das nossas duas amostras apresentaram

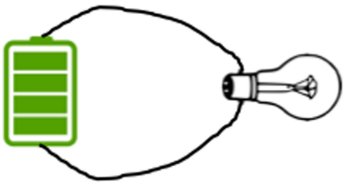

(A)

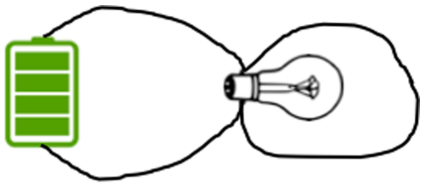

(B)
Figura 3: Diagramas apresentados na questão 18 do Direct, v. $1.0[44,45]$. respostas mais satisfatórias. Em vez de 67/70, tivemos aqui $31 / 44$. Todavia, não sabemos se esses percentuais realmente correspondem a modelos mentais cientificamente mais bem estruturados ou ao acaso.

O Aluno6 apresentou durante a entrevista a mesma resposta que havia dado quando respondeu ao teste escrito, ou seja escolheu a alternativa incorreta B. Essa resposta é idêntica àquela dada pela maioria dos alunos do estudo de Engelhardt [45]. Tendo em vista a consistência das respostas dada pelo Aluno6 durante a entrevista, resolvemos realizar uma segunda entrevista clínica com ele exclusivamente sobre a questão 4 (ver material suplementar), uma vez que ela permite extrair outras informações sobre concepções alternativas relatadas na literatura.

Entre os sete entrevistados, quatro demonstraram claramente raciocinar com o Modelo III, ou seja a corrente não pode ser influenciada por um elemento onde ainda não passou. Esses respondentes disseram que o brilho de L1 permanece o mesmo, porque:

- ao fechar o interruptor não será alterado o brilho de L1 (Aluno2);

- como a L1 está antes da L2, o interruptor não afeta a L1 (Aluna4);

- L2 que vai dividir com o que será fechado, e L1 ficaria com o mesmo brilho (Aluna5);

- a corrente já passou por L1, e eu acho que não vai mudar (Aluno7).

\subsubsection{Questão 6}

A questão 6 (Fig. 4) também tem o objetivo de investigar a capacidade do respondente para identificar o estado de curto-circuito. A lâmpada L1 da questão 4 foi substituída por um resistor, e o esquema do circuito foi ligeiramente alterado. Não podemos afirmar se essa leve alteração no diagrama foi responsável pelos resultados diferentes, ou se os resultados diferentes decorreram da falta de consistência na manipulação conceitual por parte dos respondentes.

Nessa questão tivemos mais acertos por parte dos alunos do ensino médio do que por parte daqueles da engenharia (78/70), mas a diferença nos parece insigni- 
6) No circuito da figura 6, R é um resistor e I é um interruptor que está aberto. Ao fechar o interruptor:

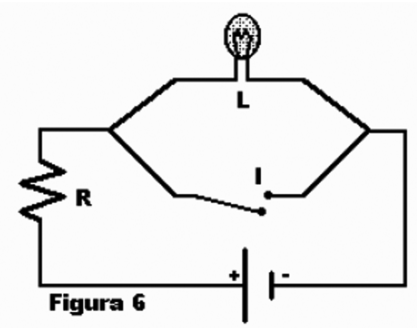

a) L continua brilhando como antes.

b) L deixa de brilhar.

c) $L$ diminui seu brilho mas não

apaga.

Figura 4: Questão 6 do teste SMA.

ficante. O que chama a atenção é a inversão percentual nas escolhas das alternativas (A) e (C), ou seja (16 e 6) para os alunos do ensino médio, e (7 e 23) para os alunos de engenharia (Tabela 1). Quem opta pela alternativa (A) não faz a menor ideia do que seja um curto-circuito. O interruptor parece ser um componente inativo. Os resultados acima sugerem que essa percepção equivocada é maior na turma EnsMed. Quem opta pela alternativa (C) parece associar uma resistência ao interruptor, que "roubará" parte do brilho da lâmpada. Essa concepção é compartilhada por mais alunos de FisII do que por alunos de EnsMed. No entanto, entre os sete entrevistados na turma EnsMed, apenas dois foram explícitos quanto a essa concepção. A Aluna5 disse que "a corrente vai ser dividida", e o Aluno7 afirmou que "o fluxo de energia será dividido".

\subsection{Questões para as quais $10<\chi^{2} \leq 50$}

Uma característica interessante das questões desse grupo, é a assimetria nas respostas dos dois grupos. Enquanto a maioria dos alunos de FisII acertou todas as questões exceto a 12, a maioria dos alunos do ensino médio só acertou a questão 10 (Tabela 5). Das questões desse grupo selecionamos a 5 e a 14 para constar nas entrevistas clínicas. As questões 10 e 12 referem-se a circuitos em paralelo, consideradas muito acima do nível dos alunos da turma EnsMed. Antes de discutirmos as questões usadas nas entrevistas, comentaremos os resultados obtidos com as questões 3 e 9 .

A questão 3, cujo enunciado é apresentado na Fig. 5, tem objetivos similares às questões 2 e 5 , qual seja investigar a existência do Modelo I e do raciocínio sequencial. Esse tipo de raciocínio leva o indivíduo a analisar um circuito em termos do "antes" e do "depois", acreditando que a corrente no circuito é influenciada por um elemento apenas quando ela o atinge [27]. Embora não haja di- ferença conceitual entre essas questões, há indicativos de que os estudantes confundem-se com a topologia do circuito $[29,44]$. Por exemplo, o aluno pode fazer uso diferente do seu modelo mental se o circuito é em série ou em paralelo, apenas pelo formato geométrico do circuito e não por influência direta de seu modelo mental. Nesse sentido, é interessante comparar os resultados das questões 2,3 e 5 . A primeira e a última serão detalhadas mais abaixo.

A alternativa (C) da questão 3 não faz sentido para nenhum dos modelos considerados aqui. Consistentemente, nenhum aluno da turma EnsMed e apenas 4\% da turma FisII escolheram essa alternativa. O interessante é verificar que houve uma inversão dos percentuais para as Alternativas (A) e (B). Na turma EnsMed, A/B=75/25, ao passo que na turma FisII, $A / B=26 / 70$. Dizer que L1 tem o mesmo brilho de L2 talvez seja um indicativo de raciocínio sequencial. O respondente imagina que a corrente parte do polo positivo, divide-se em partes iguais e que só vai diminuir depois que passar por L1, pois uma parte será consumida pela resistência. Para os alunos de EnsMed essa resposta é inconsistente com aquela dada na questão 2. Como veremos mais adiante, $84 \%$ dos respondentes da turma EnsMed responderam na questão 2, que L2 brilha mais que L1, sugerindo que eles imaginam a corrente circulando do polo negativo para o positivo, e que é parcialmente consumida ao passar pela resistência.

Embora os alunos de FisII indiquem a existência do raciocínio sequencial, eles são consistentes quanto ao sentido da corrente, uma vez que na questão 2 apenas $5 \%$ escolheram a alternativa (C). Pode também ser sinal de consistência quanto ao raciocínio sequencial e ao sentido da corrente, o fato de $26 \%$ da turma FisII terem escolhido a alternativa (B) na questão 2, e a alternativa (A) na questão 3 .

A resposta correta na questão 3, alternativa (B) pode mascarar a concepção alternativa do consumo de corrente.

Tabela 5: Percentuais das respostas corretas nos dois grupos de alunos nas questões para as quais $10<\chi^{2} \leq 50$. Alternativas corretas entre parênteses.

\begin{tabular}{lcccccc}
\hline Questão (alternativa correta) & $3(\mathrm{~B})$ & $5(\mathrm{~B})$ & $9(\mathrm{~A})$ & $10(\mathrm{C})$ & $12(\mathrm{~B})$ & $14(\mathrm{C})$ \\
\hline Ensino Médio & 25 & 13 & 47 & 69 & 3 & 26 \\
\hline Física II-C & 70 & 75 & 87 & 88 & 38 & 58 \\
\hline
\end{tabular}




\section{3) No circuito da figura 3, $R$ é um resistor. Neste circuito:}

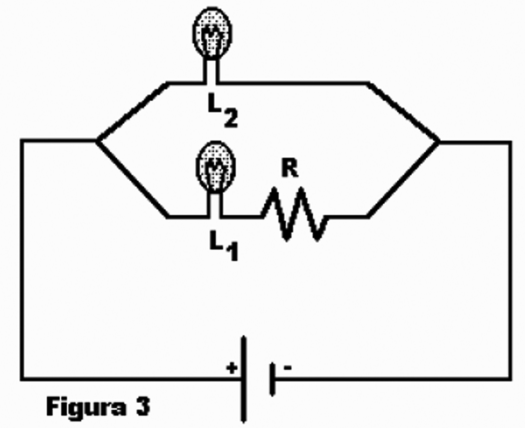

a) $L_{1}$ tem o mesmo brilho de $L_{2}$.

b) $L_{2}$ brilha mais do que $L_{1}$.

c) $L_{1}$ brilha mais do que $L_{2}$.

Figura 5: Questão 3 do teste SMA.

O respondente pode escolher a alternativa (B), não pelo aumento da resistência do ramo em paralelo, mas por meio do seguinte raciocínio equivocado: a corrente sai do polo negativo, divide-se em partes iguais, mas uma parte é consumida pela resistência o que resulta em menor brilho em L1. Esse aspecto não foi investigado nesse estudo. Será objeto de um estudo com entrevistas clínicas planejado para investigar o mascaramento de concepções alternativas em questões de testes similares ao presente.

A questão 9 (Fig. 6) objetiva investigar se o respondente usa o conceito de conservação de carga, ou conservação espacial de corrente. Se o aluno conhece o conceito de conservação dessas grandezas, não importa o que exista entre L1 e L4, o brilho das duas tem que ser o mesmo. Entre os alunos da turma EnsMed, $47 \%$ escolheram a alternativa correta. $15 \%$ dos alunos disseram que L1 brilha mais que L4. Provavelmente esses alunos imaginam a corrente circulando do polo positivo para o negativo e parte dela sendo consumida por L2 e L3. 38\% disseram que L1 brilha menos que L4. Provavelmente esses possuem a mesma concepção alternativa do consumo, mas imaginam que a corrente circula do polo negativo para o positivo.

A questão 14, que foi usada nas entrevistas clínicas, também tem como um dos objetivos investigar se o res- pondente trabalha com o conceito de conservação de carga e corrente.

\subsubsection{Questão 5}

Conforme discutimos acima, a respeito da questão 3, essa questão 5 do teste SMA (Fig. 7) objetiva a investigação do raciocínio sequencial. Quem opera com o raciocínio sequencial e imagina a corrente circulando do polo positivo para o negativo, escolherá a alternativa (a), pois a corrente será consumida na resistência que fica depois da lâmpada. Por outro lado, quem tem essa concepção e imagina que a corrente circula do polo negativo para o positivo escolherá a alternativa (c). Ou seja as duas escolhas são consistentes com o raciocínio sequencial e só diferem na definição do movimento de deriva dos portadores. O que é importante, do ponto de vista didático, é ter em mente que essa concepção viola a lei da conservação espacial da corrente.

Aproximadamente $87 \%$ dos alunos da turma EnsMed e $25 \%$ dos alunos FisII operam com o raciocínio sequencial. Dos sete alunos da turma EnsMed selecionados para a entrevista clínica, quatro exibiram essa concepção alternativa. Dois optaram pela alternativa (a), pois a corrente circulando do polo positivo para o negativo não será diminuída na lâmpada que está antes da resistência. Os

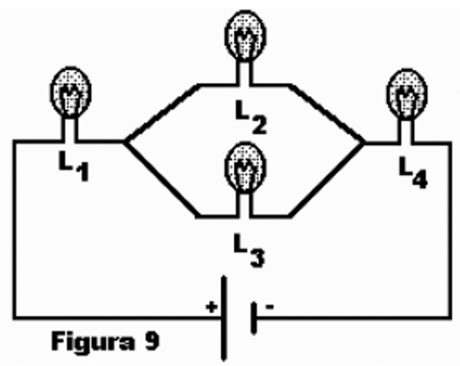

9) No circuito da figura $9 \circ$ brilho de $L_{1}$ é :
a) igual ao de $L_{4}$.
b) maior do que o de $\mathrm{L}_{4}$.
c) menor do que o de $\mathrm{L}_{4}$.

Figura 6: Questão 3 do teste SMA. 
5) Nos circuitos $5 a$ e $5 b$ a lâmpada $L$, o resistor $R$ e a bateria são exatamente os mesmos. Nestas situações:

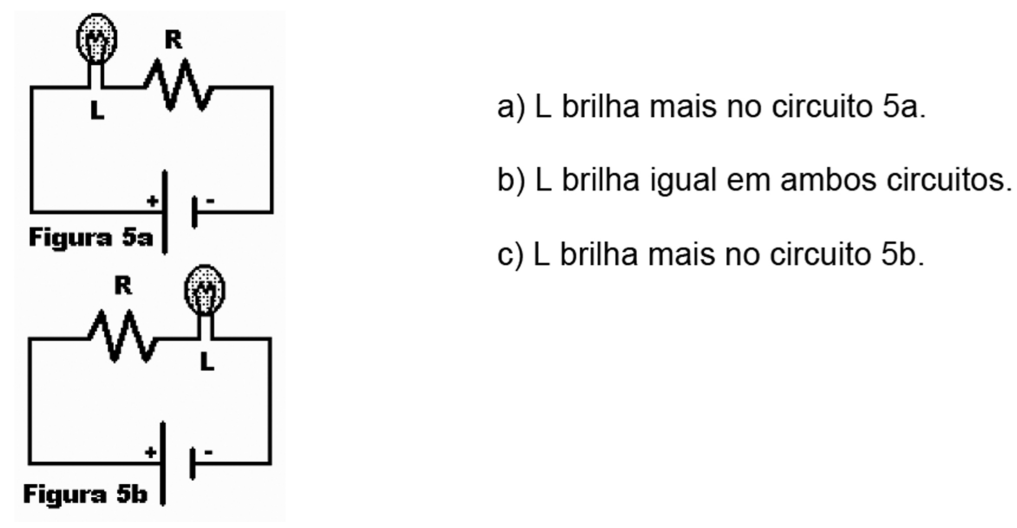

Figura 7: Questão 5 do teste SMA.

outros dois optaram pela alternativa (c) e apresentaram a mesma justificativa utilizando o argumento de que a corrente circula do polo negativo para o positivo.

A essa mesma conclusão chegaram Shipstone e colaboradores [27] a partir de uma questão com um circuito similar ao nosso. Nos cinco países estudados por esses autores (Alemanha, França, Holanda, Inglaterra e Suécia), a proporção de alunos com o raciocínio sequencial variou de $30 \%$ a $45 \%$, faixa na qual incluem-se os alunos da turma FisII. Por outro lado, na turma EnsMed a proporção de alunos com o raciocínio sequencial é quase o dobro.

\subsubsection{Questão 14}

A questão 14 (Fig. 8) objetiva investigar se o respondente possui o conceito de conservação espacial de corrente; se domina a ideia de que a corrente fornecida pela bateria depende da montagem ou da alteração do circuito. Também está envolvido na questão o papel do curto-circuito. O enunciado não é explícito, mas a questão envolve duas situações. Com o interruptor ligado ou desligado. Está implícito que com o interruptor fechado as lâmpadas L3 e L4 brilham. Ou seja, ao abrir o interruptor diminui a corrente no circuito, isto é, não há conservação temporal da corrente.
Conforme consta na Tabela 1, apenas 25\% dos alunos da turma EnsMed escolheram a opção correta (c), ao passo que $69 \%$ escolheram a opção (b) que indica a inexistência do conceito de conservação espacial de corrente.

Essa questão é bem mais complexa do que as anteriores e permite a investigação de vários aspectos dos modelos mentais preservados pelos alunos. Por exemplo, a informação de que as lâmpadas L3 e L4 deixam de brilhar quando o interruptor é aberto tem alto grau de complexidade que deve ser explorado em entrevistas clínicas. Os livros didáticos costumam abordar circuitos com o uso simbólico de seus componentes (baterias, resistores, capacitores e indutores) e aplicar a lei de Ohm e as leis de Kirchhoff e raramente conectam tais símbolos aos dispositivos reais. Essa prática didática dificulta a interpretação de circuitos quando questões práticas são levantadas. É o caso da dificuldade que os alunos têm em relacionar a intensidade da corrente com o brilho de uma lâmpada. De um modo geral eles não se dão conta que se a intensidade da corrente for abaixo de determinado valor (que depende da resistência da lâmpada), a lâmpada não brilha. E a ausência de brilho é interpretada como inexistência de corrente.

Dos sete alunos selecionados para entrevista clínica, dois escolheram a opção (a), dois a opção (b) e três a

14) No circuito da figura 12, quando o interruptor é aberto, as lâmpadas $L_{3}$ e $L_{4}$ deixam de brilhar, embora $L_{2}$ brilhe. $O$ que acontece com as lâmpadas $L_{1}$ e $L_{5}$ ?

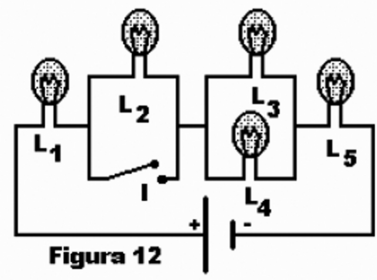

a) nem $L_{1}$, nem $L_{5}$ brilham.

b) $L_{1}$ brilha e $L_{5}$ não brilha.

c) $L_{1}$ e $L_{5}$ brilham.

Figura 8: Questão 14 do teste SMA. 
opção (c), no teste escrito. Durante as entrevistas alguns deles mudaram de opinião, como se verá a seguir.

\subsection{Alunos que escolheram a opção (a) no teste escrito}

$\mathrm{Na}$ entrevista a Aluna3 não lembrou da resposta no teste escrito e escolheu a letra (b), porque L5 estava conectada a L3 e L4, e essas não brilhavam porque "ficavam sem circulação de energia". Quando arguida, reconheceu que havia energia no circuito por causa do brilho em L1, mas não soube explicar para onde foi a energia que não chegava em L3, L4 e L5.

A Aluna4 também mudou para (b): "Porque se L3 e L4 não brilham, a energia não passa por elas e não tem como chegar em L5.

\subsection{Alunos que escolheram a opção (b) no teste escrito}

A Aluna5 confirmou a escolha do teste escrito: "Já que as lâmpadas L3 e L4 param de brilhar, a próxima também não brilha". Quando questionado não soube explicar para onde foi a corrente que passara por L1 e L2.

Mais uma vez, as respostas do Aluno6 apresentam consistência, mesmo quando orientadas por concepções equivocadas. Ele não manteve a resposta do teste escrito, mudou para (c), mas o diálogo com o entrevistador é muito instrutivo, como pode ser visto no material suplementar.

\subsection{Alunos que escolheram a opção (c) no teste escrito}

A Aluna1 não lembrou a resposta que havia dado no teste escrito e escolheu a alternativa (b) "porque tem um interruptor ligado com uma lâmpada de modo a poder controlar a corrente". Quando solicitada a narrar o percurso da corrente, disse que não sabia. Disse que a energia só passa por L1 e L2, mas não sabia para onde ela ia depois disso.

O Aluno2 confirmou a seleção anterior, "se L2 brilha, consequentemente L1 e L5 brilham". Quando solicitado a explicar por que L5 brilha se L3 e L4 não brilham, ele mudou a resposta para (b). Esse tipo de comportamento, demonstrado por outros em outras circunstâncias é similar àquele descrito por Posner e colaboradores e por eles denominado de acomodação conceitual [51]. O aluno indica o caminho da acomodação: "Como L3 e L4 não brilham, então somente L1 brilha". No seu processo de acomodação ele apenas considerou a declaração da alter- nativa (b), ignorando o enunciado da questão, segundo o qual L2 também brilha.

O Aluno7 mudou para a alternativa (a), "porque o circuito fica muito pesado, por causa da quantidade de lâmpadas". Quando questionado para explicar por que as lâmpadas residenciais não se apagam, pediu para trocar a resposta. Escolheu a letra (c). Quando questionado o porquê de L3 e L4 não brilharem, respondeu que era "porque a energia não passava totalmente por causa do interruptor aberto". Quando solicitado a explicar o porquê de L5 brilhar, se L3 e L4 não brilham, pediu novamente para trocar a resposta. Escolheu (b), "porque a energia não tem força para acender um lado do circuito".

\subsection{Questões para as quais $\chi^{2}>50$}

Das questões com maiores discrepâncias entre as respostas (Tabela 6), selecionamos apenas a questão 2 para constar nas entrevistas clínicas, pois ela revela um dado muito importante a ser considerado nos cursos sobre eletricidade no ensino médio, qual seja o desconhecimento por parte dos alunos de que uma lâmpada incandescente não é nada mais do que uma resistência.

A questão 2 (Fig. 9) é formalmente idêntica à questão 1. No entanto, enquanto todos os alunos da turma EnsMed acertaram a questão 1 , apenas $7 \%$ acertaram a questão 2. Por outro lado, $84 \%$ optaram pela alternativa (c) e $9 \%$ pela (b). É bem verdade que as entrevistas mostraram que as respostas ao teste escrito não são confiáveis. Há uma proporção indeterminada de respostas ao acaso.

As alternativas (b) e (c) correspondem ao Modelo I, sendo que a primeira está associada à ideia de que a corrente sai do polo positivo, enquanto que para quem opta pela segunda a corrente circula no circuito a partir do polo negativo. Então, se esses números são confiáveis, podemos dizer que mais de $84 \%$ da turma pensa que a corrente circula a partir do polo negativo.

Na entrevista com a Aluna3, ela repetiu a opção (c), justificando que por causa do resistor, a energia que passa por L1 não tem a mesma intensidade da que passa por L2. Ou seja, para ela a corrente circula do polo negativo para o positivo, e o resistor é um consumidor de energia. A associação da corrente elétrica com o consumo de energia é muito recorrente e talvez tenha algo a ver com o efeito Joule, mas essa é uma questão em aberto.

A Aluna4 justificou a escolha da letra (b) com o argumento de que "a energia, depois de passar por L1 tem dificuldade de passar pela resistência, como se a energia ficasse com menos força, então L2 vai receber menos energia".

Tabela 6: Percentuais das respostas corretas nos dois grupos de alunos nas questões para as quais $\chi^{2}>50$.

\begin{tabular}{lcccc}
\hline Questão (alternativa correta) & $2(\mathrm{~A})$ & $7(\mathrm{C})$ & $11(\mathrm{~B})$ & $13(\mathrm{~A})$ \\
\hline Ensino Médio & 7 & 3 & 3 & 6 \\
\hline Física II-C & 69 & 38 & 38 & 79 \\
\hline
\end{tabular}




\title{
2) No circuito da figura 2, $R$ é um resistor. Neste circuito:
}

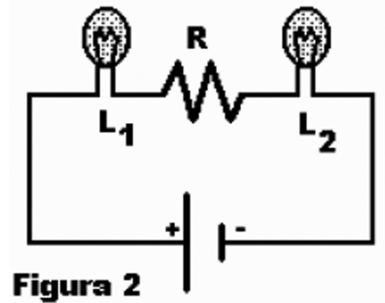

\author{
a) $L_{1}$ e $L_{2}$ têm o mesmo brilho. \\ b) $L_{1}$ brilha mais do que $L_{2}$. \\ c) $L_{2}$ brilha mais do que $L_{1}$.
}

Figura 9: Questão 2 do teste SMA

No teste escrito a Aluna5 tinha escolhido a letra (c), mas na entrevista mudou para (a), dizendo que a situação era idêntica à da questão 1 . Na questão 1 ela havia dito que as lâmpadas apresentavam o mesmo brilho porque estando em série recebiam a mesma energia. Quando o entrevistador quis saber qual era o sentido da corrente, a aluna disse ser nos dois sentidos, "porque as lâmpadas precisam tanto de prótons, como de elétrons, daí ela tem que receber os dois ao mesmo tempo". Esta aluna apresenta claramente o raciocínio conforme o Modelo II.

Para o Aluno6, L2 brilha mais do que L1 "porque o resistor vai limitar a corrente". Como na questão anterior, este aluno adota o conceito de resistor como limitador da corrente provavelmente influenciado por cursos técnicos que ele frequentou no IFCE.

Em suma, além de permitir a exibição de concepções alternativas já reportadas na literatura, essa questão mostra considerável prevalência da associação de corrente elétrica a um fluxo de energia. Tanto quanto sabemos, não há na literatura um estudo sistemático abordando essa questão, apesar de a mesma ser frequentemente reportada $[27,29,34,44,48]$.

\section{Comentários finais}

O resultado mais notável obtido neste estudo talvez seja a confirmação da recorrência de concepções alternativas relatadas na literatura. Muitos dos artigos mencionados aqui referem-se a esse fenômeno, entre os quais podemos destacar o trabalho de Shipstone e colaboradores [27], que estudaram essa questão em cinco países europeus, e Solano e colaboradores [31], que investigaram a persistência de concepções alternativas sobre circuitos elétricos de corrente continua em alunos na faixa etária entre 11 e 18 anos, ou seja do ensino médio ao primeiro ano universitário.

Praticamente todos os resultados relatados por esses autores foram confirmados em nosso estudo. Por exemplo, confirmou-se aqui a prevalência da ideia de que a bateria é uma fonte de corrente elétrica constante. Essa concepção equivocada gera outras concepções alternativas, como o raciocínio local e o raciocínio sequencial. Além disso, alguns alunos associam a corrente elétrica a um fluxo de energia. É provável que a concepção do consumo de corrente venha da ideia do consumo de energia em nosso cotidiano. Este é um resultado que deve ser seriamente considerado nas sequências didáticas do assunto. Há que se trabalhar a discriminação entre corrente elétrica e energia.

Outro resultado notável, ao qual devemos dar muita atenção em estudos dessa natureza, é a falta de consistência nas respostas ao teste escrito. Isso pode ter a ver com o fenômeno da acomodação conceitual, estudado por Posner e coladores [51]

Por exemplo, todos os alunos da turma EnsMed acertaram a primeira questão do teste, sugerindo a inexistência da ideia do consumo de corrente. Mas, na entrevista alguns mudaram a resposta e exibiram a concepção alternativa. Também apresentaram indícios da ideia do consumo de corrente (ou de energia), exibindo inconsistência no raciocínio, ao responder a segunda questão, que difere da primeira apenas pela substituição de uma das lâmpadas por uma resistência. Aparentemente, alguns alunos não percebem que uma lâmpada incandescente é apenas um resistor. Quando um resistor é colocado no circuito, a ideia do consumo de corrente emerge mais facilmente.

O teste escrito e as entrevistas salientam uma questão que deve ser cuidadosamente examinada nas sequências didáticas, qual seja a falta de correlação entre dispositivos elétricos reais (fios, lâmpadas, baterias, etc) e suas representações gráficas nos circuitos. Esse caso é particularmente relevante para os interruptores. As entrevistas com os sete alunos sugerem que poucos alunos sabem a função de um interruptor.

\section{Agradecimentos}

À CAPES pela bolsa concedida a Francisco Andreázio Lôbo de Andrade, durante a realização do Mestrado Nacional Profissional em Ensino de Física, na UFERSA.

\section{Material Suplementar}

O seguinte material suplementar está disponível online: Suplemento 


\section{Referências}

[1] P. Freire, Educação E Mudança, 31st ed. (Paz e Terra, São Paulo, 2008) p. 69.

[2] J.S. Bruner, Uma Nova Teoria de Aprendizagem, 3a. (Bloch Editores, Rio de Janeiro, 1975) p.49.

[3] J.S. Bruner, Am. Psychol. 19, 1 (1964).

[4] L.S. Vygotsky, Mind in Society. The Development of Higher Psychological Processes (Harvard University Press, Cambridge, 1978) p. 84.

[5] K. Lewin, Psychol. Rev. 50, 292 (1943).

[6] R.K. WHITE, Psychol. Rev. 50, 157 (1943).

[7] E.C. Tolman, Psychol. Rev. 56, 144 (1949).

[8] F. Heider, J. Soc. Issues 15, 3 (1959).

[9] D.P. Ausubel, J. Educ. Pshychology 51, 267 (1960).

[10] D.P. Ausubel, J. Teach. Educ. 14, 217 (1963).

[11] D.P. AUSUBEL, Psychol. Sch. 6, 331 (1969).

[12] M.A. Moreira and E.F.S. Masini, Aprendizagem Significativa: A Teoria de David Ausubel (Moraes, São Paulo, 1982) p.112.

[13] C.A. dos Santos and M.A. Moreira, Rev. Bras. Física 9, 835 (1979).

[14] C.A. dos Santos and M.A. Moreira, Rev. Bras. Física 9, 859 (1979).

[15] C.A. dos Santos and M.A. Moreira, Rev. Bras. Física 9, 849 (1979).

[16] M.A. Moreira and C.A. dos Santos, J. Res. Sci. Teach. 18, 525 (1981).

[17] P.N. Johnson-Laird, Cogn. Sci. 4, 71 (1980).

[18] A.T. Borges and K. Gilbert, Int. J. Sci. Educ. 21, 95 (1999).

[19] A.T. Borges, Rev. Ens. 1, 66 (1999).

[20] I.M. Greca and M.A. Moreira, Int. J. Sci. Educ. 22, 1 (2000).

[21] L. Viennot, Le Raisonnement Spontané En Dynamique Élémentaire. Tese de Doutorado. Université Paris VII, 1977.

[22] R. Driver, A. Squires, P. Rushworth, and V. WoodRobinson, in Mak. Sense Second. Sci. Res. into Child. Ideas (Routledge, London, 1994), pp. 117-125.

[23] J. Clement, J. Res. Sci. Teach. 30, 1241 (1993).

[24] P. Potvin, É. Turmel, and S. Masson, Front. Hum. Neurosci. 8, 1 (2014).

[25] S. Masson, P. Potvin, M. Riopel, and L.-M.B. Foisy, Mind, Brain, Educ. 8, 44 (2014).

[26] M.E. Dominguez and M.A. Moreira, Rev. Enseñanza La Fis. 2, 7 (1988).

[27] D.M. Shipstone, C. v. Rhöneck, W. Jung, C. Kärrqvist, J.-J. Dupin, S. Johsua, and P. Licht, Int. J. Sci. Educ. 10, 303 (1988).

[28] F.L. Silveira, M.A. Moreira, and R. Axt, Cienc. Cult. 41, 1129 (1989).

[29] L.C. McDermott and P.S. Shaffer, Am. J. Phys. 60, 994 (1992).

[30] P.S. Shaffer and L.C. McDermott, Am. J. Phys. 60, 1003 (1992).

[31] F. Solano, J. Gil, A.L. Pérez, and M.I. Suero, Rev. Bras. Ensino Física 24, 460 (2002).

[32] J.-W. Lin, EURASIA J. Math. Sci. Technol. Educ. 13, 3009 (2017).

[33] R. Osborne, Res. Sci. Technol. Educ. 1, 73 (1983).

[34] D.M. Shipstone, Eur. J. Sci. Educ. 6, 185 (1984).
[35] R. Cohen, B. Eylon, and U. Ganiel, Am. J. Phys. 51, 407 (1983).

[36] N. Fredette and J. Lochhead, Phys. Teach. 18, 194 (1980).

[37] F.L. da Silveira, in Fúsica No Ensino Médio Falhas E Soluções, edited by J.B. Rocha Filho (Edipucrs, Porto Alegre, 2011).

[38] R. Duit and C. Rhoneck, in Connect. Res. Phys. Educ. with Teach. Educ., edited by A. Tiberghien, E.L. Jossem, and J. Barojas (International Commission on Physics Education, Singapura, 1998).

[39] D. Halliday and R. Resnick, Física Básica, Vol. 3 (Livros Técnicos e Científicos, Rio de Janeiro, 1981).

[40] M.A. Moreira, Aprendiz. Significativa Em Rev. 1, 43 (2011).

[41] A. Gonçalves Filho and C. Toscano, Física - Interação E Tecnologia 3, 1a. (Editoa Leya, São Paulo, 2013) p. 216.

[42] J. Posner, George and W. GERTZOG, Sci. Educ. 66 195 (1982).

[43] J. Lucariello and D. Naff, Am. Psychol. Assoc. 1 (2012).

[44] P.V. Engelhardt and R.J. Beichner, Am. J. Phys. 72, 98 (2004).

[45] P.V. Engelhardt, Examining Students' Understanding of Electrical Circuits through Multiple-Choice Testing and Interviews. Tese de Doutorado, North Carolina State University, 1997.

[46] J. Evans, Phys. Teach. 16, 15 (1978).

[47] M.E. Dominguez and M.A. Moreira, Rev. Enseñanza La Fis. 2, 7 (1988).

[48] S.M. Stocklmayer and D.F. Treagust, Int. J. Sci. Educ. 18, 163 (1996).

[49] H. Urban, Sci. Educ. 8, 285 (2017).

[50] C. Smaill, G. Rowe, and E. Godfrey, in Proc. 2009 Annu. Conf. Expo. Am. Soc. Eng. Educ. (2009), p. 14.673.214.673 .15

[51] G. POSNER, K. STRIKE, P. HEWSON, and W. GERTZOG, Sci. Educ. 66, 211 (1982). 